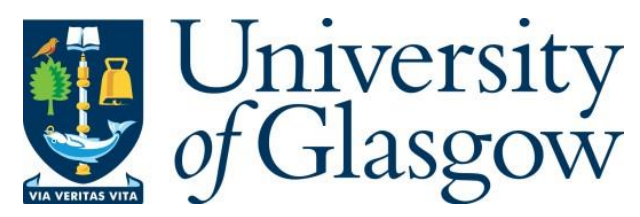

Barton, P. S., Evans, M. J., Foster, C. N., Pechal, J. L., Bump, J. K., Quaggiotto, M.-M. and Benbow, M. E. (2019) Towards quantifying carrion biomass in ecosystems. Trends in Ecology and Evolution, 34(10), pp. 950-961.

There may be differences between this version and the published version. You are advised to consult the publisher's version if you wish to cite from it.

http://eprints.gla.ac.uk/221216/

Deposited on: 3 August 2020

Enlighten - Research publications by members of the University of Glasgow http://eprints.gla.ac.uk 


\section{Towards quantifying carrion biomass in ecosystems}

2

3 Philip S. Barton ${ }^{1 *}$, Maldwyn J. Evans ${ }^{1}$, Claire N. Foster ${ }^{1}$, Jennifer L. Pechal ${ }^{2}$, Joseph K.

4 Bump $^{3}$, M.-Martina Quaggiotto ${ }^{4}$, M. Eric Benbow ${ }^{2,5}$

5

$6{ }^{1}$ Fenner School of Environment and Society, Australian National University, Canberra, ACT, 7 2601, Australia.

$8 \quad{ }^{2}$ Department of Entomology, Michigan State University, East Lansing, MI, USA

$9{ }^{3}$ Department of Fisheries, Wildlife, and Conservation Biology, University of Minnesota,

10 Saint Paul, Minnesota, 55108, USA

$11{ }^{4}$ Institute of Biodiversity, Animal Health and Comparative Medicine, University of Glasgow,

12 Scotland, G12 8QQ

$13{ }^{5}$ Department of Osteopathic Medical Specialties, Michigan State University, East Lansing,

14 MI, USA

*Corresponding author: philip.barton@anu.edu.au 


\section{Abstract}

19 The decomposition of animal biomass (carrion) contributes to the recycling of energy and

20 nutrients through ecosystems. Whereas the role of plant decomposition in ecosystems is

21 broadly recognised, the significance of carrion to ecosystem functioning remains poorly

22 understood. Quantitative data on carrion biomass is severely lacking and there is no clear

23 pathway towards improved knowledge in this area. Here we present a framework to show

24 how quantities derived from individual carcasses can be scaled up using population metrics,

25 allowing for comparisons among ecosystems and other forms of biomass. Our framework

26 facilitates the generation of new data that is critical to building a quantitative understanding of

27 carrion's contribution to trophic processes and ecosystem stocks and flows.

30 Keywords: animal, biogeochemical cycling, carcass, decomposer, decomposition, detritus, necrobiome, necromass, scavenger 


\section{GLOSSARY}

36 Autotrophic biomass - Organic matter derived from primary producers via photosynthesis.

37 Carcass - Intact or partially consumed body of a dead animal, including invertebrates and

38 vertebrates.

39 Carrion - The dead tissues from whole or part of an animal.

40 Decomposition - Process of decay and breakdown of organic matter.

41 Heterotrophic biomass - Organic matter derived from animals or other consumers.

42 Necrobiome - The community of decomposers and their interactions associated with

43 decomposing organic matter. 
The decomposition of organic matter disperses energy and nutrients concentrated by living organisms back into the biosphere $[1,2]$. The critical importance of decomposition for ecosystems is made conspicuous by the absence of substantial accumulated dead biomass in most ecosystems [3, but cf. peatlands 4]. Yet there is a significant lack of data on ecosystem inputs from dead animal biomass (carrion, see Glossary) - a distinct form of heterotrophic biomass. This means we are unable to answer the question of whether carrion contributes fundamentally to ecosystem nutrient budgets and functioning. Currently we know that animal carcasses (including collective invertebrate carrion) enhance ecosystem heterogeneity by adding unusually concentrated resource hotspots [5-7], and support a suite of highly dependent species that provide valuable ecosystem services by consuming and recycling carrion $[5,8-10]$. These contributions of carrion to biodiversity and ecosystem processes are distinct in key ways from plants, e.g. the timescale of biomass turnover [5, 6], suggesting a need to quantify carrion biomass and its role in ecosystem function. The data to answer this question are scarce, however, and there exists no framework to guide research in this area. For this reason, carrion remains a 'hidden' resource that has not been adequately incorporated into ecosystem models of resource stocks and flows [1, 11], and its importance is largely overlooked except following unusual or notable cases of mass mortality [12-14]. A critical first step to bridging this gap is to develop approaches to derive quantitative estimates of carrion inputs to ecosystems, and thus generate the data necessary to include heterotrophic biomass beside autotrophic biomass in ecosystem models.

We describe a framework that links knowledge gained from studies of individual carcasses to population-, community-, and ecosystem-level processes, enabling new estimates of carrion biomass at different ecological scales. We think that such estimates will be critical to emerging research on: how carrion enters an ecosystem detritus pool $[14,15]$; the speed and mechanisms by which carrion nutrients are released $[13,15,16]$; the transfer of resources 
among ecosystems [17-19]; and the contribution of carrion to ecosystem services $[8,20]$ and global biodiversity $[6,7,12,21-23]$.

\section{What do we know about carrion biomass in ecosystems?}

Theoretical models of ecosystem energetics and trophic structure that incorporate dead biomass have historically focused on the contribution of plant-derived biomass and downplayed (or ignored) the contribution of animal-derived biomass [e.g. 1, 3, 24], [but see 11]). Yet, application of these resource models still requires quantitative estimates of biomass, and such estimates are broadly lacking for carrion.

Globally, animal biomass is estimated to be $2 \mathrm{Gt}$, which is a fraction of global biomass of plants (450 Gt), bacteria (70 Gt), or fungi (12 Gt) [25]. Within terrestrial ecosystems, estimates of $30,400 \mathrm{~kg} / \mathrm{km}^{2}$ of animal biomass ( $0.03 \%$ of total biomass) have been given for an east African savanna [26], 20,000 kg/ $\mathrm{km}^{2}$ of animal biomass $(0.02 \%$ of total biomass $)$ in a central Amazonian rainforest [27], and $434 \mathrm{~kg} / \mathrm{km}^{2}$ of vertebrate biomass $(0.06 \%$ of aboveground biomass) in a shrub-steppe ecosystem of the USA [28]. While animals clearly constitute a small relative percentage of total biomass, their effect on ecosystems via the production of carrion is likely to be disproportionate relative to equivalent amounts of plant biomass. This is because quantity alone does not predict impact, with biomass quality, quantity, and rate of turnover also affecting ecosystem structure and function [29]. The nutrient-rich and dynamic properties of carrion, and the numerous specialist species that it supports [5], mean that for a full understanding of ecosystem function it is critical to treat this heterotrophically-derived resource separately from plant biomass. But how much carrion biomass is there, and how might we find out?

We examined the literature for reports of carrion biomass in ecosystems (see Appendix 1). We found 26 studies that presented information about the number, density, or biomass of animal carcasses, with biases towards fish in freshwater systems, ungulates in 
terrestrial systems, and episodic, mass die-offs (e.g. following salmon spawning or insect emergence events) (Appendix 2 and Appendix 3). Estimates that included spatial information $(n=19)$ showed there is little knowledge of the carrion biomass of most taxa from the majority of biomes (see Figure 1, Appendix 2).

Carcass size ranged over 10 orders of magnitude, from marine copepods $(0.00003 \mathrm{~g})$ up to moose $(400,000 \mathrm{~g})$ (Figure 1a). We found that carcass densities were highest for very small animals (e.g. 10 billion copepods $/ \mathrm{km}^{2}$ ) and lowest for larger animals (e.g. 1 moose or impala $/ \mathrm{km}^{2}$ ). Notable densities relative to body size included salmon ( 1 million carcasses $/ \mathrm{km}^{2}$ ) and bivalves ( 1 billion carcasses $/ \mathrm{km}^{2}$ ). Such densities were often localized to particular hotspots, such as specific reaches of streams and rivers, and represent an extraordinary concentration and release of nutrients.

When expressed as biomass density $\left(\mathrm{kg} / \mathrm{km}^{2}\right)$, bivalves, salmon, and midges represented the upper end of the range of 100,000 to $10,000,000 \mathrm{~kg}$ of carrion $/ \mathrm{km}^{2}$ (Figure $1 \mathrm{~b}$, $\mathrm{n}=17$ ). By contrast, copepods and ungulates were at the lower end of the range (between 10 and $1000 \mathrm{~kg} / \mathrm{km}^{2}$ ), despite being vastly different in body size. Studies of invertebrate carcasses were rare, but included measurement of midge density emerging from lakes, with estimates of up to $150,000 \mathrm{~kg} / \mathrm{km}^{2}$ [30]; scirtid beetle carcasses weighing $0.0004 \mathrm{~g}$ supplemented leaf litter as food for mosquito larvae [31]; and mass emergence and die-off of cicadas, each weighing $0.73 \mathrm{~g}$, and their effect on arthropod scavenger communities [32] and forest soils [12]. Studies of vertebrate carrion gave estimates of moose carcasses resulting from human hunting contributing carrion at densities of up to $857 \mathrm{~kg} / \mathrm{km}^{2}$ [33]. There were several studies of migratory salmon biomass input to North American streams (Appendix 2). Several studies reported large episodic inputs of carrion or mass mortality events [e.g. $13,14,34]$ demonstrating how large, concentrated inputs of carrion can have important and long-term impacts on ecosystems, including via spatial resource subsidies $[13,35]$. Yet these examples are in many ways the exception, and provide little insight into the significance of 
the more widespread, constant, and hidden inputs of carrion biomass occurring within ecosystems.

\section{Carrion is hidden because scavenging and decomposition is fast and efficient}

The unique contribution of carrion biomass to ecosystem energetics, structure, and function is, in part, a result of its high concentration of nutrients, and the speed at which these nutrients are returned to the ecosystem. The carbon:nitrogen ratio is typically much lower for carrion than plant material [36], and carrion tissues are more metabolically rewarding than the majority of plant tissues. This makes carrion highly sought after by a diversity of efficient decomposer and scavenger organisms that comprise the necrobiome. These organisms are responsible for consuming, metabolizing, assimilating, excreting, and dispersing carrion tissues. Rapid turnover is also a key reason why carrion is typically not around long enough to be noticed or measured, and why it should not be grouped with plant detritus resource pools.

Mass loss of organic matter is typically quantified using a negative exponential equation: $\mathrm{y}=\mathrm{e}^{-\mathrm{kt}}$, where $y$ is the mass, and $k$ is the rate of decay per unit time $(t)[16,24]$. Rates of decay of plant leaf litter usually range between $k=0.1$ and 4 [37], whereas carrionderived nutrients are typically released back into the biosphere at rates 10-100 times faster. For example, decay rates of $k=0.008$ to 0.014 have been reported for rats (Rattus rattus) [16], $k=0.046$ for cicadas (Magicicada sp.) [32], $k=0.088$ for salmon (Oncorhynchus sp.) [38], and $k=0.058$ for ducks (Anas acutas) or $k=0.061$ for trout (Oncorhynchus mykiss) [39]. A large body of literature also exists in the forensic sciences, where decay rates are reported for different mammal species under different environmental conditions [e.g. 40, 41], but often these studies include vertebrate scavenger exclusion, a potential confounding variable in extrapolating decay rates to more natural conditions. The above examples highlight that nutrient recycling and trophic processes occur on much faster timescales for carrion than most plant tissues. 


\section{A new framework to guide estimation of carrion in ecosystems}

150

151

152

We present a framework that links knowledge derived from individual carcasses to populations, communities, and ecosystems (Figure 2). Our broad goal is to show how carrion biomass can be estimated at a range of ecological scales within ecosystems. This can help researchers to answer fundamental questions about quantities of carrion, how carrion is distributed spatially and temporally, how it is partitioned among consumers and the environment, or how much is available at any particular point in time or space (Outstanding Questions). This can give critical perspective to local-scale studies of carrion decomposition or scavenging by placing them into a broader ecosystem context. Our framework also reinforces the need to measure carrion biomass in a consistent way, within defined spatial and temporal boundaries, to generate data useful for models of ecosystem energetics and function.

\section{a) Individual carcasses}

The foundation to understanding resource effects on ecosystem structure and function is knowledge of both biomass and its turnover [29]. For carrion, it must necessarily begin at the scale of individual carcasses, with data on body mass, its consumers, and decay rate essential to estimating carrion quantity, how it is partitioned through consumers and the environment, and its turnover (Figure 2a, 2d). Body mass of individual carcasses provides the basic unit for multiplication to larger scales. The pathways by which carcass nutrients re-enter the environment include: consumption by vertebrates $[42,43]$ or invertebrates $[10,44,45]$; assimilation by microbes present on the carrion or nearby substrates [46-48]; entering the soil $[7,16,49,50]$; entering the water column $[15,39]$; or entering the atmosphere [51]. This information is valuable because it allows for extrapolation from the individual carcasses to estimates of population-level inputs for a defined area (Box 1). 
174 flow into different consumer groups or the environment is a major hurdle to the development 175 of empirical and conceptual models of carcass effects on ecosystems. A broader knowledge base is needed to understand how the importance of each pathway changes in different ecosystem or scavenger community contexts. For example, some carcasses of animals might be entirely consumed by scavengers, whereas others may only be partly consumed $[52,53]$, take much longer to be consumed [42] or have more recalcitrant parts of the body (e.g., bones or shells). Simple models can be helpful to partition a carcass into its different environmental sinks and consumers pathways [e.g. carcass $=$ soil + insects + vertebrates + atmosphere $]$. This formula is deliberately general, and can easily be applied to total mass (including moisture) or to single components of interest such as carbon, nitrogen, phosphorus, or other nutrients $[16,54]$. The equation can also incorporate time (e.g. a differential balance approach to quantify rates of loss and gain) to understand how carcass components are differentially recycled back into the environment. For example, a long-term study of nutrient cycling from drowned wildebeest revealed that soft tissues decomposed in 2-10 weeks, whereas bones took turnover rates [e.g. 56, 57]. The spatial distributions of populations can give information 
concentrated inputs [49]. To derive population-level estimates of carrion biomass, the average mass of a carcass of a species (or mass of a particular nutrient within the carcass) can be multiplied by the number of carcasses entering the carrion pool per unit area and time (e.g. $\mathrm{kg} / \mathrm{km}^{2} / \mathrm{yr}$ ) (Figure 2b). This approach has been used effectively in a study of nutrient flow from wildebeest carcasses in the Mara River, Kenya [13]; measurements of nutrients in individual carcasses were combined with the estimates of numbers of carcasses produced from annual mass drownings. Per year, approximately $50 \%$ of carrion-derived carbon from drowned wildebeest flowed into watershed foodwebs or was released into the atmosphere, whereas $95 \%$ of carrion phosphorus remained in bones [13]. This study made explicit the contribution of dead animals to ecosystem function and the subsequent maintenance of downstream fish communities.

Multiplicative approaches to scaling from local to landscape scales are frequently used in soil ecology literature [e.g. 58] and studies of ecosystem energetics [27, 29]. It is common practice to convert nutrient or biomass data into standardized units of mass per unit area and time (e.g. $\mathrm{kg} / \mathrm{km}^{2} / \mathrm{yr}$ or $\mathrm{kg} / \mathrm{ha} / \mathrm{yr}$ ), thus allowing for comparisons across contrasting systems (Box 2). A similar approach has long been used in studies of animal biomass and secondary production in aquatic ecosystems $[59,60]$. A mass-per-unit-area approach should be applied to studies of carrion biomass in terrestrial systems so that data are presented consistently, the contribution of carrion to ecosystems is easily comparable across disparate taxa, and the importance of carrion is able to be accurately estimated relative to other resource pools [ $[18$, $61]$.

Estimating the spatial and temporal patterns of mortality for animal populations can be particularly challenging due to the combination of demographic processes, predator-prey dynamics, and landscape factors $[49,56,62]$. There are ways to integrate prey behaviour and predation risk information into carrion biomass estimates [49, 63], and this can generate knowledge of the spatial distribution of carcass nutrient inputs across landscapes (Box 3). 
Such studies demonstrate the role of behaviour and trophic linkages in determining carrion effects on ecosystems [64, 65]. Concepts such as the 'landscape of fear' [sensu 66] or 'landscape of disgust' [sensu 67] are therefore relevant to estimating population-level factors influencing carrion quality and quantity (Figure 2b), and could be incorporated into speciesspecific models of carcass inputs where predation risk is known to affect the spatial distribution of populations and animal deaths.

\section{c) Communities}

Animal communities consist of species spanning a wide spectrum of sizes, abundances, life history traits, and population dynamics. The general body size-abundance relationship illustrates that most animal species are small and only a few are large [68]. This relationship is a useful way to conceptualise the distribution and inputs of carrion in ecosystems (Figure 2c).

Yet what is needed are generalisable body size - decay rate or time-to-consumption relationships (standardised by temperature and humidity). Such models do not yet exist, however, and would greatly benefit the scaling of carcass-level data to community levels. For example, approximate abundance and density profiles with decay rates could be assigned to different sized carcasses (e.g., size spectra), and scaling factors applied to move between carcass size classes. For example, a 'small' size class might be considered 100 times more abundant and decay at twice the rate as a 'large' carcass, which is 10 times the size. Similarly, smaller vertebrate carcasses are more likely to be consumed in their entirety in a short time frame (when scavengers are not satiated). Large vertebrate carcasses (e.g., ungulates, elephants, whales), on the other hand, are more likely to be only partially consumed by scavengers [42], with remains entering the ecosystem through distinct invertebrate and vertebrate consumers. Actual values of size-dependent effects still require empirical measurement for a range of species, but this principle would allow for coarse and rapid scaling of carrion inputs generated by whole animal communities across body size classes. 
253 Knowledge of carrion at ecosystem scales can be developed from scaling-up population- or community-level estimates directly or via models. This might be achieved by multiplying community or population data by the geographic area of the ecosystem of interest, while acknowledging the spatio-temporal variation in carrion inputs. This idea is complicated, however, by seasonality in animal populations, and the difficulty in surveying carrion biomass at any moment in time due to variable inputs and its rapid turnover rates. Plant litter surveys, by contrast, can be conducted using routine measures of litter depth, volumes, or density along transects because of relatively even spatial distribution and with long turnover rates. Analogous surveys of animal carcasses are not so straight forward, but might, for example, be achieved using bone surveys of larger vertebrates $[69,70]$. One approach to scaling-up biomass production in ecosystems is the calculation of secondary production via the instantaneous growth rate method, whereby the mean growth rate of a population is multiplied by its collective living biomass [71]. This information can be used to estimate the energy channeled through populations into biomass production [72], and is used, for example, to quantify secondary production in aquatic systems and fisheries management $[72,73]$.

Variation from steady state conditions can provide information about mortality rates and carrion production. Another option is to take a top-down approach. Ecosystem-scale studies of plant litter decomposition and carbon budgets have employed total and differential mass balance approaches $[24,74]$. The mass balance equation $[$ Input $=$ Output + Accumulation $]$ is a simple mathematical expression of the principle of conservation of mass $[74,75]$. When applied to carrion, this equation reveals that the quantity of carrion cycled through decomposition pathways should equal the annual production of carrion only if the mass of carrion present in the ecosystem remains constant. Both instantaneous growth rate and mass balance approaches are well-understood and robust starting points for conceptualizing the flux 
of nutrients among resource pools of animal populations or communities in ecosystems [74, 75]. Furthermore, these approaches are amenable to scaling with ecosystem net primary productivity (NPP) and total biomass (and thus ratios of animal/plant or dead/live, Figure 2). This means that a generalised carrion budget established for one ecosystem [e.g. 57, 65] could be compared to other ecosystems, if differences in NPP are known.

\section{Implications and concluding remarks}

Our framework allows for new questions to be asked about how carrion decomposition processes occurring at one scale have implications at other scales (see Outstanding Questions). For example, knowledge of the quantity of nitrogen flowing from a carcass into nearby plants [e.g. 7, 76], flies [e.g. 53, 77] or vertebrate scavengers [e.g. 43] can now be placed within a multiplicative framework to predict quantities and their short- and long-term consequences at larger scales. Further, our framework links a key set of ecological concepts that can be used to estimate the contribution of carrion biomass to ecosystems in terms of the quantity and quality of nutrients, the spatial density of carcasses, the timeframes of nutrient release, and the trophic pathways of nutrient transfer. This framework is essential for placing carrion on the same conceptual footing as plant-derived biomass, and the future development of more complete ecosystem models of resource stocks and flow.

\section{Knowledge of ecosystem structure and function will benefit from a clearer} understanding of resource biomass and turnover [29]. It is critical to expand our knowledge of carrion inputs to ecosystems, because inputs in some cases are changing drastically. For example, new estimates of the global distribution of animal biomass indicate a six-fold decrease in the mass of wildlife and a four-fold increase in humans and livestock over the last few hundred years [25]. This substantial redistribution of animal biomass has produced a massive but unquantified change in the contribution of carrion decomposition to nutrient cycling in the terrestrial biosphere. The same is true for marine systems, where commercial 
whaling practices have led to one of the largest examples of wildlife exploitation by humans, resulting in a massive loss of animal biomass [78]. There are also other, more localised changes to carrion inputs in some ecosystems. For example, in Europe, carcasses of large vertebrate species and livestock are removed from grazing landscapes to meet veterinary or health regulatory requirements [79-81], thus leaving landscapes devoid of large carrion. Additionally, there has been an increase in frequency of wildlife mass mortality events due to disease outbreaks or starvation [14], extreme shifts in abiotic conditions [82], as well as greater attention to annual migrations and mass drownings [13]. Declines in apex predator populations around the world [83] also means that carrion inputs are changing, and in some cases contributing to an overabundance of large herbivores $[56,84,85]$. In all these cases, changes to the quantity, quality, location, or timing of inputs of carrion biomass to ecosystems have occurred. The consequences of available carrion due to these perturbations include shifts in nutrient pools, or changed pathways of nutrient flow through biotic communities, with further unknown ramifications for ecosystems (Outstanding Questions). Our conceptual framework, coupled with improved and standardized empirical methodology $[13,52,57]$, provides a way to generate the data and calculations necessary to understand the implications of these changed carrion inputs for biogeochemical cycling and resource flow, and therefore ecosystem health and function $[17,86]$.

Once quantitative data from a range of biomes and animal taxa are derived, a new perspective becomes possible that allows heterotrophic biomass to be conceptualised in a similar way to autotrophic biomass. Future efforts to discover the contribution of carrion biomass to ecosystems is fundamental to a comprehensive, mechanistic, and predictive understanding of ecosystem functioning - one that allows the unique temporal and spatial properties of carrion to be incorporated into models of ecosystem resource stocks and flow. 
329 Acknowledgements

330 PSB was funded by the Australian Research Council (DE150100026). JKB was supported by

331 grants from the United States National Science Foundation (NSF ID\#1545611, NSF

332 ID\#1556676).

333

334 Additional information

335 Supporting Information is available for this paper at $\operatorname{xxxxxxxx.}$

336 
Figure 1. Summary of some quantitative estimates of carrion from the empirical literature, showing (a) the negative log-log relationship between published carcass size and density, and (b) estimates of carrion biomass for a range of different taxa. Different colours represent different taxa. Raw data is given in Appendix 3.

Figure 2. Linkages between individual carcasses, populations, communities, and ecosystems can facilitate the estimation of carrion biomass at each scale. (a) Individual carcasses provide the base unit for scaling up carrion biomass in ecosystems. Key metrics: Carcass mass, decay rate, and composition all provide information that might be of interest at larger scales. Carcass nutrients can be routed through different consumers or ecosystem compartments (e.g. insect vs. vertebrate scavengers, microbes, or liquids or gases into the soil or atmosphere). (b) Populations provide information about numbers of carcasses entering an ecosystem from different species of animals, as well as their distribution and temporal inputs. Key metrics: multiplication of carcass-level data by population-level data is the first step to scaling up carcass biomass that can be expressed as input rates. (c) Communities provide information about relative abundances and body sizes among species. Key metrics: multiplication of population-level inputs by community-level body size and decay rate factors can generate data about relative contributions by multiple species. (d) Ecosystem-scale estimates of carrion biomass can be developed from scaling up population- and community-level quantities via secondary production methods. Mass-balance approaches provide a top-down approach to estimate carrion biomass as a function of changes to steady-state conditions. Key metrics: ecosystem carrion estimates provide data about total quantities and turnover, and is critical for broader context when partitioning total biomass into live $v s$. dead or plant $v s$. animal. 
Rabbit (Oryctolagus cuniculus) populations have established in much of southern Australia, contributions by scaling up carcass-level biomass data. A hypothetical population of 100 rabbits $/ \mathrm{km}^{2}$, with a turnover of 50/yr, each with a mass of $1.5 \mathrm{~kg}$, and assuming no direct predation, gives a total potential carrion input of $75 \mathrm{~kg} / \mathrm{km}^{2} / \mathrm{yr}$. It is possible to partition this resource pool into different nutrient components and recycling pathways [54, 77]. For example, one study showed $22 \%$ of the mass of a rabbit carcass was converted to fly larvae biomass, and $13.6 \%$ entered the soil as either moisture or nutrients [54]. From an input of 75 $\mathrm{kg} / \mathrm{km}^{2} / \mathrm{yr}$, this represents $16.5 \mathrm{~kg}$ into fly larvae and $10.2 \mathrm{~kg}$ into soil. Further, the $16.5 \mathrm{~kg}$ of fly larvae biomass represents approximately 180,000 potential adult flies [54]. Partial consumption of carcasses by vertebrates could be estimated, and incorporated as a simple factor that modulates or down-scales these estimates.

We can extrapolate from the above case study to estimate: What is the contribution of carrion biomass to invertebrate populations? For example, kangaroo (Macropus giganteus) populations can reach densities of up to two kangaroos/ha in the same study area as the above rabbit example [87]. At $30 \mathrm{~kg}$ per animal, this equates to $6000 \mathrm{~kg} / \mathrm{km}^{2} / \mathrm{yr}$ of live biomass. If $10 \%$ of the kangaroo population turned over each year, the input of carrion would be 600 $\mathrm{kg} / \mathrm{km}^{2} / \mathrm{yr}$ eight times that of rabbits, equating to $132 \mathrm{~kg}$ of potential fly larvae biomass (assuming a similar conversion rate). This study begins to build a community-level profile of carrion inputs (Figure 2c). Scaling carrion to a standardized unit allows for comparisons with other forms of biomass (Figure 2d). In the same study system, for example, a dominant perennial grass is Themeda australis, with a mean biomass of $50.6 \mathrm{~kg} / \mathrm{ha}$ [88], or 5,060 $\mathrm{kg} / \mathrm{km}^{2}$. In relative terms, therefore, rabbit and kangaroo carrion annual inputs of $675 \mathrm{~kg} / \mathrm{km}^{2}$ is approximately $1 / 8^{\text {th }}$ that of a dominant grassland plant species. The general insight from our 
389 framework is that multiplication of per-carcass data (Figure 2a) by population attributes

390 (Figure 2b) within a spatial and temporal window allows for estimates of key resource stocks 391 and flows, and can facilitate the comparison of resource types within an ecosystem.

392 
The grey seal (Halichoerus grypus) colony on the Isle of May (45 hectares, Scotland, UK) generates substantial quantities of carrion in the form of placentae and dead seals. In late

October, approximately 2000 pups are born, of which $13.3 \%$ die from natural causes [57].

Aerial and ground surveys have been used to estimate the mean annual number of placentae and seal carcasses (both pups and adults) deposited into the island and littoral ecosystem during each pupping season [57]. A total of $6,893 \mathrm{~kg}$ of carrion was found to be generated every year [3,124.3 $\mathrm{kg}(74.9 \mathrm{SE})$ of placentae, 3,768.2 $\mathrm{kg}$ (713.7 SE) of carcasses]. This quantitative knowledge of carrion biomass is rare, and allows for additional calculations to determine the contribution of carrion to ecosystem processes. For example, the total carrion biomass corresponded to $110.5 \times 10^{3} \mathrm{MJ} / \mathrm{yr}$ of energy, with $68.1 \times 10^{3} \mathrm{MJ} / \mathrm{yr}(\mathrm{SE}=1.64)$ delivered as placentae and $42.4 \times 10^{3} \mathrm{MJ} / \mathrm{yr}(\mathrm{SE}=10.42)$ as carcasses [57]. Further, they established that the total biomass scavenged by vertebrates (mostly gulls) was $1,032 \mathrm{~kg}$, and this represented $12.8 \times 10^{3} \mathrm{MJ}$ of energy cycled through vertebrate consumers. Placed into our dynamics.

The role of carrion biomass in the energetics and function of island ecosystems can often be disproportionate relative to other forms of biomass, and when compared to mainland ecosystems $[18,35]$. This disparity is highlighted, for example, by the 22 times greater production of seal carrion (equivalent to $15,317 \mathrm{~kg} / \mathrm{km}^{2}$ ) than the combined production of rabbit and kangaroo carrion described in the previous case study (i.e., $675 \mathrm{~kg} / \mathrm{km}^{2}$ ). This simple extrapolation of data, and comparison across environments, quickly highlights the 417 relative importance of carrion in contrasting ecosystems. 
On Isle Royale, USA, the moose (Alces alces) population has varied between approximately 500 and 2,000 animals over the last 60 years (1958 to 2018), and the predation rate [proportion of moose killed annually by wolves (Canis lupus)] has been greater than $20 \%$ in some years. Studies of the localized effects of carcasses on soil and plants have shown that wolf kill sites exhibit elevated soil nutrients, microbial biomass, and leaf nitrogen at levels $\sim 40-300 \%$ greater than reference sites (Figure I) [49]. Combining these localized 'percarcass' data with information about carrion distribution and wolf killing success can generate landscape-level knowledge of carrion effects on ecosystems [49]. This example of local to landscape carrion scaling is embedded within our framework (linkages between panels Figure $2 a>2 b>2 c>2 d$ ), and shows how principles from population biology can be linked with data of localized nutrient inputs to reveal novel interpretation and estimates of carrion biomass. mosaics of resource heterogeneity that help maintain microbial and plant diversity [49, 92].

Figure I. Scaling of local to landscape carrion effects was undertaken at Isle Royale National Park, USA, by quantifying the long-term ( 1958-2016) influence of wolves on carrion resource heterogeneity via moose carcass distribution. Localized carcass effects (upper left) 
445 included elevated soil nutrients (N, P, \& K), microbial biomass (bacterial and fungal

446 phospholipids fatty acids, PLFAs) and plant foliar nitrogen [49]. Understanding how wolves

447 contributed to carcass effects across the island landscape (lower and upper right) was

448 achieved by relating carcasses from wolf kills versus natural starvation. Values $>1$ indicate

449 areas where carcass distribution is more influenced by wolves and values $<1$ indicate where

450 carcass distribution is more influenced by moose starvation (values of 1 indicate equal

451 influence). Wolves travel along shorelines which results in higher predation close to the

452 water, such as (A) a river drainage, (B) an isthmus, (C) a harbour, and (D) a peninsula.

453 


\section{References}

455 1. Moore, J.C., et al. (2004) Detritus, trophic dynamics and biodiversity. Ecol Lett 7, 584-600

456 2. Handa, I.T., et al. (2014) Consequences of biodiversity loss for litter decomposition across biomes. Nature 509, 218-221

3. Gessner, M.O., et al. (2010) Diversity meets decomposition. Trends Ecol Evol 25, 372-380

4. Belyea, L.R. (1996) Separating the effects of litter quality and microenvironment on decomposition rates in a patterned peatland. Oikos 77, 529-539

5. Benbow, M.E., et al. (2019) Necrobiome framework for bridging decomposition ecology of autotrophically- and heterotrophically-derived organic matter. Ecol Monogr 89, e01331

6. Barton, P.S., et al. (2013) The role of carrion in maintaining biodiversity and ecological processes in terrestrial ecosystems. Oecologia 171, 761-772

7. Bump, J.K., et al. (2009) Ungulate carcasses perforate ecological filters and create biogeochemical hotspots in forest herbaceous layers allowing trees a competitive advantage. Ecosystems 12, 996-1007

8. Mateo-Tomas, P., et al. (2017) Both rare and common species support ecosystem services in scavenger communities. Glob Ecol Biogeogr 26, 1459-1470

9. Hill, J.E., et al. (2018) Effects of vulture exclusion on carrion consumption by facultative scavengers. Ecology and Evolution 8, 2518-2526

10. Barton, P.S., and Evans, M.J. (2017) Insect biodiversity meets ecosystem function: differential effects of habitat and insects on carrion decomposition. Ecol Entomol 42, 364-374

11. Getz, W.M. (2011) Biomass transformation webs provide a unified approach to consumerresource modelling. Ecol Lett 14, 113-124

12. Yang, L.H. (2004) Periodical cicadas as resource pulses in North American forests. Science 306, $1565-1567$

13. Subalusky, A.L., et al. (2017) Annual mass drownings of the Serengeti wildebeest migration influence nutrient cycling and storage in the Mara River. Proc Natl Acad Sci U S A 114, 76477652

14. Fey, S.B., et al. (2015) Recent shifts in the occurrence, cause, and magnitude of animal mass mortality events. Proc Natl Acad Sci U S A 112, 1083-1088

15. Beasley, J.C., et al. (2012) Carrion cycling in food webs: comparisons among terrestrial and marine ecosystems. Oikos 121, 1021-1026

16. Parmenter, R.R., and MacMahon, J.A. (2009) Carrion decomposition and nutrient cycling in a semiarid shrub-steppe ecosystem. Ecol Monogr 79, 637-661

17. Gounand, I., et al. (2018) Meta-ecosystems 2.0: rooting the theory into the field. Trends Ecol Evol 33, 36-46

18. Polis, G.A., and Hurd, S.D. (1996) Linking marine and terrestrial food webs: Allochthonous input from the ocean supports high secondary productivity on small islands and coastal land communities. Am Nat 147, 396-423 
19. Quaggiotto, M.M., et al. (2018) Seal carrion is a predictable resource for coastal ecosystems. Acta Oecol 88, 41-51

20. Morales-Reyes, Z., et al. (2015) Supplanting ecosystem services provided by scavengers raises greenhouse gas emissions. Scientific Reports 5, 7811

21. Hocking, M.D., and Reynolds, J.D. (2011) Impacts of salmon on riparian plant diversity. Science 331, 1609-1612

22. Steyaert, S., et al. (2018) Special delivery: scavengers direct seed dispersal towards ungulate carcasses. Biol Lett 14, 20180388

23. Moleón, M., et al. (2015) Carcass size shapes the structure and functioning of an African scavenging assemblage. Oikos 124, 1391-1403

24. Swift, M.J., et al. (1979) Decomposition in terrestrial ecosystems. Blackwell Scientific Publications

25. Bar-On, Y.M., et al. (2018) The biomass distribution on Earth. Proceedings of the National Academy of Sciences (USA) 115, 6506-6511

26. Hendrichs, H. (1970) Estimates of ungulate biomass in the thornbush savanna north and west of the Serengeti steppe in East Africa following a new procedure and remarks on the biomass of other herbivorous species. Saugetierk. Mitt. 18, 237-255

27. Fittkau, E.J., and Klinge, H. (1973) On biomass and trophic structure of the central amazonian rain forest ecosystem Biotropica 5, 2-14

28. Parmenter, R.R., and MacMahon, J.A. (2009) Carrion decomposition and nutrient cycling in a semiarid shrub-steppe ecosystem. Ecol Monogr 79, 637-661

29. Odum, E.P. (1962) Relationships between structure and function in the ecosystem. Jpn J Ecol $12,108-118$

30. Dreyer, J., et al. (2012) Lake-derived midges increase abundance of shoreline terrestrial arthropods via multiple trophic pathways. Oikos 121, 252-258

31. Harshaw, L., et al. (2007) Decaying invertebrate carcasses increase growth of Aedes triseriatus (Diptera : Culicidae) when leaf litter resources are limiting. J Med Entomol 44, 589-596

32. Yang, L.H. (2006) Interactions between a detrital resource pulse and a detritivore community. Oecologia 147, 522-532

33. Lafferty, D.J.R., et al. (2016) Moose (Alces alces) hunters subsidize the scavenger community in Alaska. Polar Biol 39, 639-647

34. Dreyer, J., et al. (2015) Quantifying aquatic insect deposition from lake to land. Ecology 96, 499-509

35. Polis, G.A., and Hurd, S.D. (1995) Extraordinarily high spider densities on islands: flow of energy from the marine to terrestrial food webs and the absence of predation. Proc Natl Acad Sci U S A 92, 4382-4386

36. Carter, D.O., et al. (2007) Cadaver decomposition in terrestrial ecosystems. Naturwissenschaften 94, 12-24 
37. Zhang, D., et al. (2008) Rates of litter decomposition in terrestrial ecosystems: global patterns and controlling factors. Journal of Plant Ecology 1, 85-93

38. Scheuerell, M.D., et al. (2005) A new perspective on the importance of marine-derived nutrients to threatened stocks of Pacific salmon (Oncorhynchus spp.). Can J Fish Aquat Sci 62, 961-964

39. Parmenter, R.R., and Lamarra, V.A. (1991) Nutrient cycling in a freshwater marsh: the decomposition of fish and waterfowl carrion. Limnol Oceanogr 36, 976-987

40. Sutherland, A., et al. (2013) The effect of body size on the rate of decomposition in a temperate region of South Africa. Forensic Sci Int 231, 257-262

41. Matuszewski, S., et al. (2014) Effect of body mass and clothing on decomposition of pig carcasses. International Journal of Legal Medicine 128, 1039-1048

42. Moleón, M., et al. (2015) Carcass size shapes the structure and functioning of an African scavenging assemblage. Oikos 124, 1391-1403

43. Wilson, E.E., and Wolkovich, E.M. (2011) Scavenging: how carnivores and carrion structure communities. Trends Ecol Evol 26, 129-135

44. Payne, J.A. (1965) A summer carrion study of the baby pig Sus scrofa Linnaeus. Ecology 46, $592-602$

45. Britton, J.C., and Morton, B. (1994) Marine carrion and scavengers. Oceanography and Marine Biology 32, 369-434

46. Lauber, C.L., et al. (2014) Vertebrate decomposition is accelerated by soil microbes. Appl Environ Microbiol 80, 4920-4929

47. Singh, B., et al. (2018) Temporal and spatial impact of human cadaver decomposition on soil bacterial and arthropod community structure and function. Frontiers in Microbiology 8, 2616

48. Metcalf, J.L., et al. (2016) Microbial community assembly and metabolic function during mammalian corpse decomposition. Science 351, 158-162

49. Bump, J.K., et al. (2009) Wolves modulate soil nutrient heterogeneity and foliar nitrogen by configuring the distribution of ungulate carcasses. Ecology 90, 3159-3167

50. Barton, P.S., et al. (2016) Substantial long-term effects of carcass addition on soil and plants in a grassy eucalypt woodland. Ecosphere 7, e01537

51. Putman, R.J. (1978) Patterns of carbon dioxide evolution from decaying carrion. 1. Decomposition of small mammal carrion in temperate systems. Oikos 31, 47-57

52. Putman, R.J. (1978) Flow of energy and organic matter from a carcass during decomposition. 2. Decomposition of small mammal carrion in temperate systems. Oikos 31, 58-68

53. Hocking, M.D., and Reimchen, T.E. (2006) Consumption and distribution of salmon (Oncorhynchus spp.) nutrients and energy by terrestrial flies. Can J Fish Aquat Sci 63, 20762086

54. Barton, P.S., et al. (2019) Nutrient and moisture transfer to insect consumers and soil during vertebrate decomposition. Food Webs 18, e00110 
55. Smith, C.R., and Baco, A.R. (2003) Ecology of whale falls at the deep-sea floor. Oceanography and Marine Biology 41, 311-354

56. Wilmers, C.C., and Getz, W.M. (2004) Simulating the effects of wolf-elk population dynamics on resource flow to scavengers. Ecol Modell 177, 193-208

57. Quaggiotto, M.-M., et al. (2018) Seal carrion is a predictable resource for coastal ecosystems. Acta Oecol 88, 41-51

58. Macdonald, B.C.T., et al. (2014) Carrion decomposition causes large and lasting effects on soil amino acid and peptide flux. Soil Biol Biochem 69, 132-140

59. Waters, T.F. (1969) Turnover ratio in production ecology of freshwater invertebrates. Am Nat $103,173-185$

60. Waters, T. (1977) Secondary production in inland waters. Adv Ecol Res 10, 91-164

61. Polis, G.A., et al. (1997) Toward an integration of landscape and food web ecology: The dynamics of spatially subsidized food webs. Annu Rev Ecol Syst 28, 289-316

62. Pereira, L.M., et al. (2014) Facultative predation and scavenging by mammalian carnivores: Seasonal, regional and intra-guild comparisons. Mammal Rev 44, 44-55

63. Wilmers, C.C., and Post, E. (2006) Predicting the influence of wolf-provided carrion on scavenger community dynamics under climate change scenarios. Glob Change Biol 12, 403-409

64. Hawlena, D., et al. (2012) Fear of Predation Slows Plant-Litter Decomposition. Science 336, $1434-1438$

65. Wilmers, C.C., et al. (2003) Trophic facilitation by introduced top predators: grey wolf subsidies to scavengers in Yellowstone National Park. J Anim Ecol 72, 909-916

66. Kohl, M.T., et al. (2018) Diel predator activity drives a dynamic landscape of fear. Ecol Monogr $88,638-652$

67. Weinstein, S.B., et al. (2018) A landscape of disgust. Science 359, 1213-1214

68. White, E.P., et al. (2007) Relationships between body size and abundance in ecology. Trends Ecol Evol 22, 323-330

69. Behrensmeyer, A.K. (1978) Taphonomic and ecologic information from bone weathering Paleobiology 4, 150-162

70. Miller, J.H. (2012) Spatial fidelity of skeletal remains: elk wintering and calving grounds revealed by bones on the Yellowstone landscape. Ecology 93, 2474-2482

71. Hynes, H.B.N., and Coleman, M.J. (1968) A simple method of assessing annual production of stream benthos. Limnol Oceanogr 13, 569-\&

72. Kimmerer, W.J. (1987) The theory of secondary production calculations for continuously reproducing populations. Limnol Oceanogr 32, 1-13

73. Allen, K.R. (1971) Relation between production and biomass. Journal of the Fisheries Research Board of Canada 28, 1573-1581

74. Olson, J.S. (1963) Energy storage and balance of producers and decomposers in ecological systems. Ecology 44, 322-\& 
75. Schlesinger, W.H. (1977) Carbon balance in terrestrial detritus. Annu Rev Ecol Syst 8, 51-81

76. Towne, E.G. (2000) Prairie vegetation and soil nutrient responses to ungulate carcasses. Oecologia 122, 232-239

77. Putman, R.J. (1977) Dynamics of the blowfly, Calliphora erythrocephala, within carrion. J. Anim. Ecol. 46, 853-866

78. Clapham, P.J., et al. (2008) Determining spatial and temporal scales for management: lessons from whaling. Mar Mamm Sci 24, 183-201

79. Margalida, A., et al. (2011) Can wild ungulate carcasses provide enough biomass to maintain avian scavenger populations? An empirical assessment using a bio-inspired computational model. PLOS ONE 6, e20248

80. Margalida, A., and Colomer, M.A. (2012) Modelling the effects of sanitary policies on European vulture conservation. Scientific Reports 2, 753

81. Morales-Reyes, Z., et al. (2017) Evaluation of the network of protection areas for the feeding of scavengers in Spain: from biodiversity conservation to greenhouse gas emission savings. $J$ Appl Ecol 54, 1120-1129

82. McDowell, W., et al. (2017) Mass mortality of a dominant invasive species in response to an extreme climate event: Implications for ecosystem function. Limnol Oceanogr 62, 177-188

83. Estes, J.A., et al. (2011) Trophic downgrading of planet earth. Science 333, 301-306

84. Gordon, I.J., et al. (2004) The management of wild large herbivores to meet economic, conservation and environmental objectives. $J$ Appl Ecol 41, 1021-1031

85. Cote, S.D., et al. (2004) Ecological impacts of deer overabundance. Annual Review of Ecology, Evolution and Systematics 35, 113-147

86. Gounand, I., et al. (2018) Cross-ecosystem carbon flows connecting ecosystems worldwide. Nature Communications 9, 4825

87. Barton, P.S., et al. (2011) Experimental reduction of native vertebrate grazing and addition of logs benefit beetle diversity at multiple scales. J Appl Ecol 48, 943-951

88. McIntyre, S., et al. (2015) Restoration of eucalypt grassy woodland: effects of experimental interventions on ground-layer vegetation. Aust J Bot 62, 570-579

89. Valeix, M., et al. (2009) Behavioral adjustments of African herbivores to predation risk by lions: Spatiotemporal variations influence habitat use. Ecology 90, 23-30

90. Willems, E.P., and Hill, R.A. (2009) Predator-specific landscapes of fear and resource distribution: effects on spatial range use. Ecology 90, 546-555

91. Laundre, J.W., et al. (2001) Wolves, elk, and bison: reestablishing the "landscape of fear" in Yellowstone National Park, USA. Can J Zool 79, 1401-1409

92. Stein, A., et al. (2014) Environmental heterogeneity as a universal driver of species richness across taxa, biomes and spatial scales. Ecol Lett 17, 866-880 